\title{
Dramaturge as midwife: the writing process within a New Zealand community theatre project
}

\author{
Fiona Graham Auckland University
}

\begin{abstract}
Political empowerment, and the enlargement of the multiculturalist cause, come from posing questions of solidarity and community from the interstitial perspective.
\end{abstract}

(Bhabha 1994: 4)

\section{Keywords}

writing process dramaturge as midwife community theatre metaphor and empowerment

In January 2008 Auckland City Council commissioned a group of artists to create a community theatre performance Our Street which involved three city suburbs where more than half the inhabitants have been born overseas. This intra-cultural project bought together young people in Aotearoa who are first- and second-generation migrants from India, Tonga, China, Rwanda, Fiji, Australia, Samoa, Niue, Somalia, the Cook Islands and Burma. In the past there had been many negative media portrayals of young people within these neighbourhoods; stories had been written about them rather than by them. Despite shared histories of deprivation and discrimination there had been fights between different youth groups, little positive interaction and much suspicion. This project aimed to create new connections, celebrate cultural diversity and encourage community pride. Commercial New Zealand theatre has been dominated by Pakeha (European New Zealand) writing with a steady growth in Maori representation (including Hone Kouka, Apirana Taylor, Briar Grace-Smith and Riwia Brown). Only since 1996 have playwrights from the Pacific region, Asia and India found a significant voice (including Oscar Kightley, David Fane, Toa Fraser, Dianna Fuemana, Lynda Chanwai-Earle and Jacob Rajan). According to Bhabha (1994), hybridity and 'linguistic multivocality' have 
the potential to intervene and dislocate the process of colonization through the reinterpretation of political discourse. Our Street provided new relationships for a changing community and challenged what it means to be a New Zealander in the twenty-first century. This article will examine the writing processes within this devising project where there was no conventional author. The participants were what Roland Barthes described as 'modern scriptors', they collaborated 'here and now' to create a text 'made of multiple writings, drawn from many cultures and entering into mutual relations of dialogue, parody and contestation' (Barthes 1977: 148). This community project employed a dramaturge rather than a writer, so when and how did the 'writing' take place? This article highlights the agency of the dramaturge within this process and explores the utility of the 'midwife' metaphor for understanding the way that successful dramaturgy can guide the writing process from conception to birth.

The creative team on Our Street was led by the Samoan director and film-maker Justine Simei-Barton; there was also a Fijian musician, an American composer, several Polynesian choreographers, a Tongan visual artist and me, a British dramaturge. All of these artists are also first- or second-generation New Zealanders who are very close to the experience of migration. At Auckland City Council the two community arts officers who chose the team and managed the project were Australian. Their choice of personnel reflected the importance of striking a balance between 'insider' and 'outsider' perspectives, what in anthropological writing is often termed the 'emic' (insider)/etic (observer) dualism (Geertz 1973). This distinction is important as it draws analytical attention to the contrasting perceptions or world-views of those who are inside and those who are outside a particular cultural framework. Oscillating between these different points of view enables a hermeneutic understanding or holistic framing of subjective views and experience. Justine Simei-Barton lives within the neighbourhood and has been an activist for Pacific Islanders for many years. She had the relationships, contacts and connections to bring the Pacific Island community 'inside' the project but she also had an active political commitment to new immigrant and refugee stories. As a British dramaturge who has worked in New Zealand for the last ten years I was very conscious of my role within a history of colonization. Where possible, it was important to exist as the 'outsider'; I aimed to work with all the groups but not 'belong' to any of them. Throughout the project I described my role as midwife rather than parent and I was engaged in the process of development rather than the provision of source material. The dramaturge/ midwife guides the text in the journey from 'inside' to 'outside', through the different development transitions and stages of labour.

The collective brief was that the artists should work through their multimedia with the different cultural groups to build a 'community' performance which would 'bring everyone together'. The project began with introductory sessions led by the Council community arts officers enabling the artists to establish a common language and vision. We had not worked together before and began very simply with ideas of meeting, greeting and food such as asking who are we and 'how do we come together?' To echo Bhabha (1994: 4) these were the questions 'of solidarity and community' which we asked of ourselves and the different groups. There were ten 
workshop weeks where the artists established relationships and introduced their media to the different communities. There were Polynesian and hip hop dance sessions, drama workshops, a reggae band was set up, art classes created a visual arts magazine and a short film was made. The director and dramaturge moved between these groups and began to document their stories. Justine worked with a mainly Polynesian drama group who began to improvise around the ideas of meeting, greeting and food. At this point the dialogue did not exist on the page, but remained inside the heads of the participants to be reinvented in each sharing.

As dramaturge I worked with an Indian theatre company 'Prayas' to develop their stories. They created a short written text titled Sticky Fingers, which was informed by their first impressions of New Zealand and experiences of immigration. My role was to ask questions and facilitate discussion, developing their ideas and stories. Open-ended questions enabled the development of a performance language and a shared group vision. What are you showing? What are you telling? What do you leave the audience to guess? This kind of questioning established characters and a storyline, which the members of Prayas scored, improvised and shaped into scenes. Sometimes one person would scribe as they worked quickly on their feet, occasionally using a tape recorder, or they would work more slowly in pairs to describe and enact the scene as they wrote together. In improvisation the writing process emerges from instant negotiation and the continuous spontaneous creation of text between actors. It is an authorless process in the conventional sense, involving a polyphony of participants or 'multiple scriptors'.

According to Barthes (1977), writing begins as soon as the text stands outside the author, once the symbol stands on the page. As he puts it, 'the disconnection occurs, the voice loses its origin, the author enters into his own death, writing begins' (Barthes 1977: 142). In this process the script is an amalgamation of different voices but once they are inscribed on the page they acquire a degree of unity. As dramaturge I made offers regarding form, structure and character development but the group made collective choices, editing and negotiating rewrites on their feet before writing it down. The dramaturge is both a 'mirror' and a mediator within this process: that is, she describes what she is seeing on the rehearsal floor and what is happening within the group. The dramaturge De Vuyst, in an interview with Turner and Behrndt (2008: 157), also uses this 'mirror' metaphor when working in dance with a choreographer: 'A dramaturge is a mirror: you reflect - literally mirror - what you see [...] the challenge is to be intellectual without being guilty of intellectualism'. I was frequently reminded of this challenge while working with the different groups involved in this project. It was important to judge the timing of interventions so that they moved the writing forward and sustained the collaboration. Just as expectant parents have to trust the midwife with the delivery of their baby, so the midwife must honour their wishes for delivery, as she assists in the process of birth.

In order to access more stories and introduce other young people to the project I led a series of writing workshops with 16-year-olds in two local secondary schools. We began by mapping their neighbourhood and sharing stories of how they came to live in their houses. This neighbourhood has 
more than twenty different languages and most of the streets have different 'worlds' side by side. Over one week the students did a 'neighbourhood watch' exercise where they kept a journal of stories from their street. This observational form of writing developed in practice and is illustrated by Jeronimo Ponifasio from Papua New Guinea, as he writes:

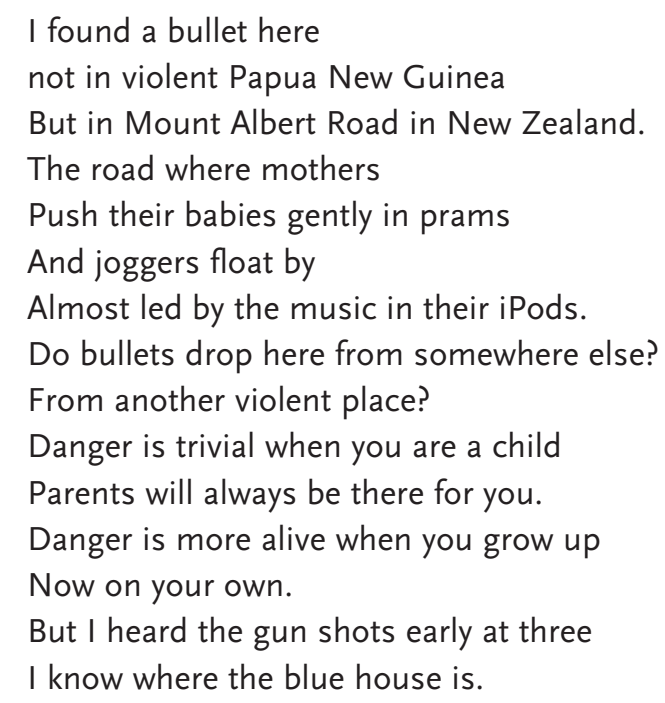

This became an important source of writing for story development, setting and character construction. The students were invited to a one-week intensive workshop where all of the work would be shared.

Another target group was the Somali women who are the most recent refugees in the neighbourhood. As director and dramaturge we developed relationships with the women by spending time attending sewing workshops, nursery sessions and a wedding celebration. Slowly they shared their stories of escape from Somalia and arrival in New Zealand but they were not ready to integrate within a large performance group so we decided to record the descriptions of their experiences through a short film. This choice empowered one woman in particular, who had been a midwife in Somalia, to mediate the experience of the group. In this storytelling process I asked the questions while the director did the filming. It seemed to offer a safer environment operating outside the pressures of performing live, and more importantly, an opportunity for the women to edit the material before sharing.

In the intensive-workshop week every group shared work in progress: there were drama scenes, monologues from the schools, Polynesian dances, songs from the reggae band, the first visual arts magazine, Sticky Fingers from Prayas and a short film. The director experimented with different performance possibilities and explored the cultural juxtapositions through film, drama, music and dance. As dramaturge I was searching for story connections, documenting key lines, reactions, observations and images. My aim was to find a central metaphor and 'bridge' (to use another dramaturgical metaphor) that could hold the material inside one cohesive structure. Shunt company member Heather Uprichard describes the dramaturge as 'a compass' helping the company to find direction (Turner and Behrndt 2008: 176). She argues that the director 'takes snapshots on the 


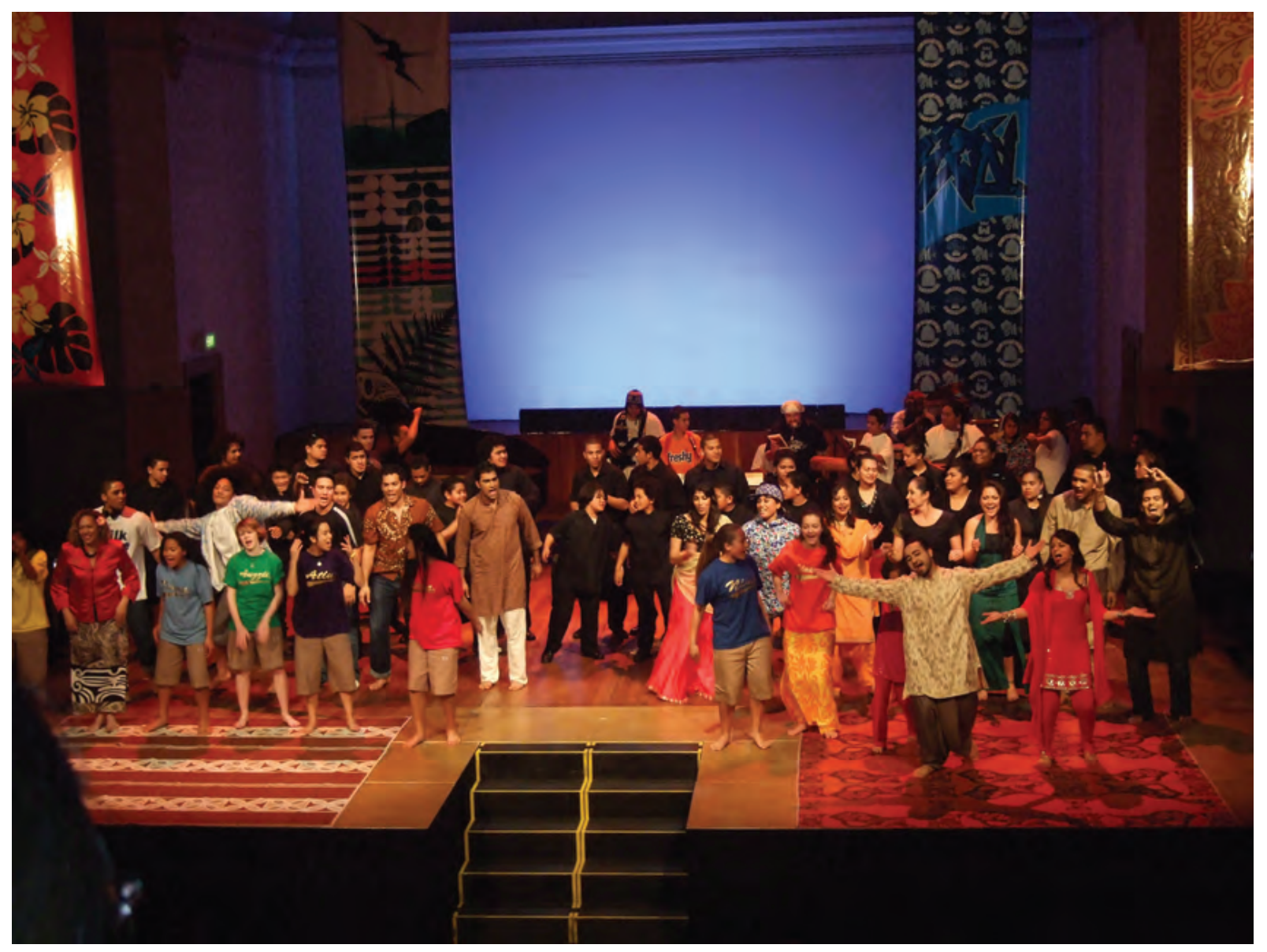

Figure 1.

ground' but the dramaturge 'holds the map of the process'. In one of the school workshops a girl had told a story about a neighbour who built a fence over the summer, each day the neighbours would stand beside him and chat. As the fence got higher and higher the neighbours spent more time together until one day it was finished and they all went back inside their own houses. The girl longed for another event that would bring them all together again. This was a powerful metaphor for the project and offered a structure for development.

At the end of the residency the artists collected their thoughts and feedback. This information suggested that the different communities had enjoyed working together and were now keen to build a much larger performance. At this point I made the most important dramaturgical intervention and pitched a multimedia storyline about a street where everyone stayed inside their own worlds - an Indian house, a Pacific Island house, a Somali house, a 'gangster' house and a Chinese house. The catalyst for change would be two mothers from the Pacific Island and Indian houses who would accidentally build a friendship through jogging together very early in the morning and meeting to chat on a bridge where their paths crossed. Their relationship would also create a bridge between the different worlds. All of the groups had been interested in wedding stories and the inciting incident, catalyst or 'fence' would be two weddings happening 
on the same day from the Indian and Pacific Island houses. Across all cultures weddings typically bring people together, providing both a rite of passage and a celebration of the coming together of different families and generations. These two weddings would enable the exploration of cultural tensions and traditions when values change in a new land, which would be shown through dance, music, film and drama. As each wedding faces a crisis, the different families would come together through the friendship between the two mothers. The resolution to these crises only came about on that day when they became a community celebrating together.

All of these ideas came from the material shared in the intensive-workshop week. However, this intervention wove the different strands together to create one story - the Our Street depicted in the play's title. Eugenio Barba describes dramaturgy as a synthesizing process, a 'weave' or 'weaving together' (Barba 1985: 75). In Our Street this weaving was facilitated through collaboration between director and dramaturge. We agreed on the importance of showing the collective process within the narrative. The metaphor of 'building fences' and the community celebration at the end of the show reflected the group's journey.

The artists supported the storyline and with the director they began to develop their different media within the structure. Over the next twelve weeks the Polynesian group and Indian group improvised and scripted their stories using the same process as on Sticky Fingers. The dramaturge and director then separated the key moments into different scenes and began to juxtapose and bring together the two groups and their stories. On one side of the stage was a Samoan-Maori wedding and on the other an Indian wedding between a Punjabi and a South Indian. It was powerful to see a young Indian girl performing a Polynesian dance and then the Polynesian youth group doing a Bollywood dance routine. At the same time the Chinese and 'gangster' house stories were developed, the 'gangster' house being inspired by text from Jeronimo Ponifasio, the student from Papua New Guinea. The director, Justine, typed the scenes and remained 'inside' the text while I, the dramaturge, strove to maintain an 'outsider's' eye. This balance meant that Justine could also explore all the performance possibilities of music, dance and film while I concentrated on structure, pace and through line. At each rehearsal the groups were creating new material with the choreographers and composer. The source material was created collectively by 'the multiple scriptors', facilitated by both the director and dramaturge, typed together by the director and edited by the dramaturge. The company finished the final draft leaving three weeks for a rehearsal period in which the director took control of performance and developed the text from the page to the stage. At this point I continued to offer feedback ever conscious of Turner and Behrndt's observation that the dramaturge must be a diplomat 'finding the right language to pose difficult, but necessary questions and sometimes make what might seem uncomfortable observations about the decisions being made' (Turner and Behrndt 2008: 182).

Barthes (1997) has argued that the unity of a text is only discovered by the reader. However, in performance that reader is the audience and in Our 
Street, which opened at Auckland Town Hall to packed houses, that audience was one of the most diverse ever seen in New Zealand. After the performances, audience members talked excitedly about seeing their worlds and experience represented on stage for the first time. In this project marginalized communities, traditionally not represented in theatre, came together and found a collective voice with status and visibility at the centre of the city. The reviewer Michael Field wrote 'It's about trying to define what our Auckland is, and how it could be in the future' (Field 2008). As Homi Bhabha observes "These "in-between" spaces provide the terrain for elaborating strategies of selfhood - singular or communal - that initiate new signs of identity, and innovative sites of collaboration, and contestation, in the act of defining the idea of society itself' (Bhabha 1994: 2). This was a polyphony of 'scriptors' writing about their lives in Auckland during 2008 and celebrating a 'vibrant multi-ethnic heart' at the centre of the city. Bhabha identifies the 'political empowerment that comes from a vision of community' that 'takes you "beyond yourself" in order to return, in a spirit of revision and reconstitution, to the political conditions of the present' (Bhabha 1994: 4). For the artists there was a sense of political empowerment that came from sharing different cultures and exploring how we could work together in new ways. For the participants the project engendered a strong sense of solidarity and collective community. Many individuals commented on how much they had discovered in common between their different cultures and how much they had been taken 'beyond themselves'.

Roland Barthes wrote that 'In ethnographic societies the responsibility for a narrative is never assumed by a person but by a mediator, shaman or relator whose "performance" - the mastery of narrative code - may possibly be admired but never his "genius"' (Barthes 1977: 142). There are some parallels here with the position of the dramaturge whose contribution can be contested or invisiblized. Like the role of the midwife it is a humble position; at the end of the birth the midwife/dramaturge departs and 'the baby' belongs to the parents.

\section{References}

Barba, E. (1985), 'The Nature of Dramaturgy: Describing Actions at Work', New Theatre Quarterly, 1 (February), pp. 75-78.

Barthes, R. (1977), Image, Music, Text, Glasgow: Fontana.

Bhabha, H. K. (1994), The Location of Culture, London: Routledge.

Field, M. (2008), 'Review: Our Street in Auckland', http://www.stuff.co.nz/ print/4657325a186o.html. Accessed 25 August 2008.

Geertz, C. (1973), The Interpretation of Cultures, New York: Basic Books.

Turner, C. and Behrndt, S. (2008), Dramaturgy and Performance, New York: Palgrave Macmillan.

\section{Suggested citation}

Graham, F. (2009), 'Dramaturge as midwife: the writing process within a New Zealand community theatre project', Journal of Writing in Creative Practice 2: 2, pp. 209-216, doi: 10.1386/jwcp.2.2.209/1 


\section{Contributor details}

Fiona Graham worked for twenty years in British theatre in education and community theatre before moving to Auckland in 2004. She is a freelance playwright and dramaturge who has taught at Auckland University, Goldsmiths College and De Montfort University. Theatre commissions include Our Street (Auckland, 2008), Breaking China (Theatre Centre UK, 2002; Singapore, 2004), Between Friends (Komedia UK, 2000; Portugal, 2001) and Legacy (Massive Theatre, Auckland, 1998).

Contact: Department of English, Auckland University, Symonds Street, Auckland, 1001, New Zealand.

E-mail: f.graham@auckland.ac.nz 